\title{
Interactive comment on "Relationship between erythema effective UV radiant exposure, total ozone and cloud cover in southern England UK: 1991-2015" by Nezahat Hunter et al.
}

\section{Anonymous Referee \#1}

Received and published: 4 October 2018

General comments:

This paper provides a sound study on long-term trends over 25 years of solar ultraviolet radiation measurements and the observations are related to ozone and cloud cover. The scientific content of the publication is certainly worth to be published in ACP.

The submitted paper is well written and organized and the data are fully described.

However, the statistical methods are based on tests, which might not be well known to the reader. I suggest including a small summary of the statistical tests or at least to citing the publications, were the methods are fully described. 
The paper can be published with this minor revision requested.

Specific comments:

Section 2.3:

Are the tests performed with all available data points? What would be the impact on the results if only a randomly chosen subset of data are selected for the tests? In other words: What is the variation of the statistical results, when a smaller of data-points are used for the calculation. Or: how robust are the statistical results.

Smaller issues:

The abstract basically describes the intention and results of the study - no changes.

The text is well written and no major typos have been detected.

Interactive comment on Atmos. Chem. Phys. Discuss., https://doi.org/10.5194/acp-2018-828, 2018. 